\title{
Minding the Protest
}

\author{
Attitudes towards different \\ forms of protest action in \\ contemporary South Africa
}

\section{Narnia Bohler-Muller, Benjamin James Roberts, Jarè Struwig, Steven Lawrence Gordon, Thobeka Radebe and Peter Alexander*}

nbohlermuller@hsrc.ac.za

broberts@hsrc.ac.za

jstruwig@hsrc.ac.za

sgordon@hsrc.ac.za

tradebe@hsrc.ac.za

palexander@uj.ac.za

http://dx.doi.org/10.17159/2413-3108/2017/i62a3041

This article focuses on providing new insights into the nature of public opinion about protest action in South Africa. Since the mid-2000s the country has experienced one of the world's highest levels of popular protest and strike action, combined with the recent resurgence of an active student protest movement. Sociological research into these protests has suggested that they represent distinct phenomena and that local protests have assumed plural forms that cut across simple violent/non-violent and orderly/disorderly binary distinctions. Despite the rapid growth of literature on South African protests, surprisingly little is known about public opinion relating to various forms of protest. Consequently, this article aims to examine differences with regard to the acceptability, perceived effectiveness and participation in respect of three categories of protest action, namely orderly, disruptive and violent protests. The article uses data from a protest module included as part of the 2016 round of the South African Social Attitudes Survey, a nationally representative series conducted annually by the Human Sciences Research Council. Apart from determining the nature and extent of variation in opinion regarding the three types of protest action on aggregate, the article explores patterns of similarity and differentiation across societal groups, based on class, age, race, gender and geography. Finally, we analyse how and for whom perspectives on the three forms of protest have changed over the course of a generation by drawing on functionally equivalent data collected in 1995. The article concludes by reflecting on whether the evidence supports key hypotheses regarding the 'rebellion of the poor' in the country.

\footnotetext{
* Narnia Bohler-Muller is executive director of the Democracy, Governance \& Service Delivery (DGSD) Research Programme at the Human Sciences Research Council. Benjamin Roberts is a senior research manager and Jarè Struwig is the chief research manager of the DGSD Research Programme. Steven Gordon is a post-doctoral researcher and Thobeka Radebe a Masters intern in the programme. Peter Alexander holds the South African Research Chair in Social Change and is the director of the Social Change Research Unit at the University of Johannesburg.
} 
South Africa has experienced a remarkable rise in local protest activities since 2004, a development that has occurred on such a scale and with such intensity that it has been referred to as insurrection or insurgency. ${ }^{2}$ Students, workers and a range of other actors increasingly employ protest tactics in their attempts at achieving social, political and economic change. These actions have been largely peaceful in character, while at other times protesters have tended to adopt more violent strategies. ${ }^{3}$ Sociological research into protests has suggested that they represent distinct phenomena and that local protests have assumed plural forms that defy straightforward classification. As such, there remains appreciable contestation regarding the nature, prevalence and determinants of these contemporary forms of protest. But despite the importance of this phenomenon for academics and policymakers, public opinion scholars have not examined how the general population views protest actions in South Africa. A growing literature exists on the likelihood of participation by and experiences of the protesters, ${ }^{4}$ but existing empirical evidence is not able to answer important questions about public attitudes towards protest action in the country. This article aims to address this knowledge gap by utilising nationally representative public opinion data to examine attitudes towards protest action in the country.

Public attitudes towards protest activity are likely to be influenced by historical context. ${ }^{5} \mathrm{At}$ the start of the post-apartheid period, South Africa had just emerged from a long struggle for democratic freedom that was characterised by protest actions. Using local and international newspaper reports, the Global Database of Events, Language and Tone, ${ }^{6}$ for example, documented 3.8 million protest events in 1979. Most of these protests, particularly in the 1980s, employed peaceful tactics. But violent protests were also utilised to bring about social and economic change. ${ }^{7}$ The level of protest dropped sharply in the 1990s but increased in 2004 and then escalated again after 2008. The Social Conflict in Africa Database (SCAD) ${ }^{8}$ has recently noted a sustained increase in the number of protests in South Africa between 2016 and 2017. The SCAD warned that violent protests were becoming more common, with communities increasingly employing protest tactics to draw attention to their grievances.

Most protest actions, particularly after 2004, seem to originate from South Africa's economically disadvantaged communities. The source of people's grievances seems to be economic in character, with protesters tending to cite the poor state of wages, labour market opportunities, municipal services and other material issues as predominant factors. Given that most protests share strong similarities in forms of contention, geographical space, organisation and demographics, it would appear that we are dealing with a broad process of protest, rather than merely a set of discrete events. Alexander has referred to this broad process as the 'rebellion of the poor'. ${ }^{9}$ Other scholars have ascribed the majority of protest actions to contestations over the full benefits of 'citizenship'. ${ }^{10}$ Given the modern trajectory of protest, we may expect to observe distinct socio-economic differences in how people view protest action in the country. A plausible hypothesis would therefore be that those in the upper echelons of South Africa's socio-economic class structure, as beneficiaries of the status quo, would be more inclined to favour social order and disapprove of protest actions as opposed to those in more vulnerable material circumstances.

The reaction of government to local protests has ranged from contrition and negotiation to autocratic obstinacy. How government responds to a specific protest action can determine how effective that action is. This, in 
turn, can have a significant effect on how the general population thinks about that action. Government's response to a specific protest can be (and should be) mediated by public opinion. The responsiveness of government policies to the preferences of citizens is an essential element of most normative and empirical theories of democracy. ${ }^{11}$ In practice, however, the policy-attitude relationship is not perfectly linear and government can enact policies that defy the popular opinion. Nonetheless, the correlation between public opinion and public policy is considered to be a moral good, a crucial characteristic of successful democratic governance.

The reaction of law enforcement to protest action in South Africa has ranged from hostility to patient observance. A number of scholars are concerned that the former is more common than the latter. Royeppen contends that the state responses to protest today are in many ways a reflection of the state response to protest during the apartheid era. ${ }^{12}$ Indeed, as the number of protests in South Africa has grown, we have seen the emergence of a highly securitised policing response. Research by Newham and Faull has shown that the police in South Africa use paramilitary tactics that disregard human rights, much to the detriment of police-community relations. ${ }^{13}$ Such heavyhanded policing can additionally lead to (or worsen) confrontations between police and protesters. Some critics have argued that the aggressive crowd control methods of the police have in many instances provoked protesters into responding with violence. ${ }^{14}$ Indeed, the manner in which the police dealt with protesters during the recent \#FeesMustFall protests raised serious concerns among commentators.

When covering the growth in protest actions, the media has often made simple violent/nonviolent and orderly/disorderly binary distinctions about these actions. Such subdivisions are reductive, biasing audiences against certain social movements and presenting a false dichotomy between 'good' and 'bad' protesters. Given the limiting nature of these dichotomies for analytical research, we adopt a more nuanced approach to categorising different types of protest action in this article. More specifically, we employ the typology proposed by Runciman et al. as the basis for our approach to understanding public attitudes towards protest action. ${ }^{15}$ Runciman and her colleagues use 'order' and 'violence' as dividing lines. Because all peaceful protests are orderly and all violent protests are disorderly, it is possible to discern a three-way categorisation: (1) peaceful; (2) disruptive (i.e. disorderly but not violent); and (3) violent. Although in practice these three forms of protest are not always mutually exclusive, we have adopted these discrete categories for the purpose of quantitative analysis and monitoring social change. ${ }^{16}$ Sociological research into these protests has suggested that these three categories represent distinct, meaningful phenomena. We believe that adopting this typology will allow us to gain a more comprehensive understanding of public attitudes towards these forms of political action. In this article, we primarily aim to examine differences with regard to the acceptability and perceived effectiveness of peaceful, disruptive and violent protest action. We begin by outlining the methodology of our study, which is followed by a presentation of findings. Apart from determining the nature and extent of variation in opinion regarding the three types of protest action on aggregate, the results section explores patterns of similarity and differentiation across societal groups, based on class, age, race, gender and geography. This leads into an analysis of the determinants of public approval for each of the three types of protest action. This will provide a sense of the nature of the differences between the three forms of protest, and whether a hierarchy of protest exists in 
the minds of South Africans. The article concludes by reflecting on possible avenues for future research.

\section{Methodology}

The data used for this study derives from two national surveys conducted by the Human Sciences Research Council (HSRC), the first in 1995 and the second in early 2017. Each survey was designed to be nationally representative of the adult population living in private households across the country's nine provinces. Participation in each survey was voluntary and the data was collected by means of face-to-face interviewing. Strict ethical guidelines were adhered to, including review and approval of instruments and protocols by a Research Ethics Committee, and the use of consent forms to provide respondents with the assurance of the confidentiality of their interview responses. The 1995 survey formed part of the HSRC's Omnibus Survey series and was conducted in February and March 1995. It was administered by MarkData, which at the time was the HSRC's survey and opinion research centre. ${ }^{17}$ The survey had a realised sample size of 2238 adults aged 18 years and older. The 2016 protest data derive from a specialised module included as part of the $14^{\text {th }}$ annual round of the South African Social Attitudes Survey (SASAS), which was conducted between January and March 2017. ${ }^{18}$ The SASAS 2016 dataset had a realised sample of 3079 people aged 16 years and older. The sample sizes of both the SASAS and Omnibus series are in line with international best practices on public opinion sampling. ${ }^{19}$ Weights were designed for both datasets and all analytical results presented in this article have been weighted to be nationally representative.

The 1995 and 2016 surveys were selected for use in this article because they are the only representative surveys in the country that distinguish between the three different types of protest action outlined by Runciman et al. ${ }^{20}$ In both surveys, respondents were told that they would be questioned about three different kinds of protest actions. The fieldworker then read out a description of a specific type of protest action and then asked how the respondent felt about that type of action. The exact phrasing of the descriptions is as follows:

- Peaceful actions: 'I mean non-violent things like worker strikes as well as attending rallies and joining marches that have been agreed to by the authorities.'

- Disruptive actions: 'I mean things that are more forceful but still non-violent, like blocking traffic with tyres, stones or other objects, as well as occupying buildings or offices.'

- Violent actions: 'I mean injuring people or destroying other people's property.'

Respondents were asked close-ended questions on how positive or negative they felt about the different types of protest action and then how successful or not they thought such actions were. Responses to each question were captured using a seven-point scale. In the case of the positive-negative questions, the scale ranged from extremely negative to extremely positive, while for the effectiveness questions, the scale ranged from extremely unsuccessful to extremely successful.

\section{A hierarchy in protest- related attitudes?}

The national distribution in responses to the questions on the image and perceived effectiveness of the three types of protest action in 2016 is presented in Figure 1. For interpretive ease, the original seven-point scaling has been collapsed into a three-point scale. The bar chart points to the existence of clear differences in the way in which the adult public perceives these forms of protest action. Peaceful action on average tends to be viewed as more positive 
Figure 1: Image and perceived effectiveness of peaceful, disruptive and violent protest action in South Africa, 2016 (\%)

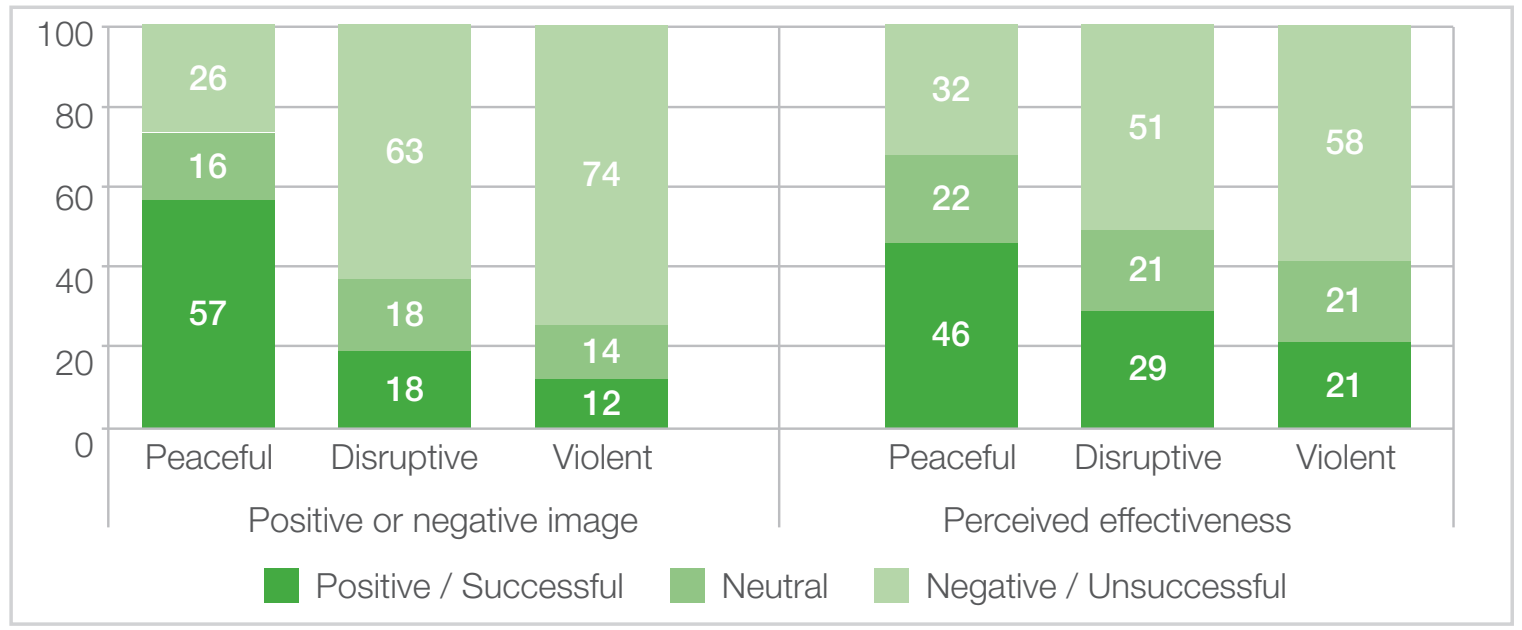

Source: HSRC SASAS R14 2016.

and effective than disruptive and violent protest action. While close to six in 10 South Africans regard peaceful protest favourably, this level of approval falls appreciably to around a fifth in the case of disruptive actions and barely a tenth in respect of violent protest actions. A similar, though marginally less acute, gradient exists in relation to perceptions of the effectiveness of these behaviours.

The comparison between image and effectiveness ratings for each of the types of protest leads to an interesting observation. For peaceful actions, the share of the population viewing it as effective (46\%) is lower than the share reporting that they view such action favourably (57\%), which indicates that a certain proportion of adults support peaceful action but remain ambivalent or sceptical about its efficacy as a form of political behaviour. By contrast, for both disruptive and violent protest actions, the share considering such actions as effective (29\% and $21 \%$ respectively) exceeds the share reporting a positive view (18\% and $12 \%)$. This implies that notable subsets of the adult population hold a negative image of such actions but do nonetheless admit that it is politically effective. Despite this, the overarching view on both the image and effectiveness of disruptive and violent protests remains largely negative in character. The question remains as to whether and how such attitudes have changed over time, especially given the rising incidence of protest-related actions since the mid-2000s.

\section{The changing nature of protest attitudes}

The responses to the attitudinal questions about the three types of protest action in both 1995 and 2016 are compared in Table 1. The top half of the table presents the distributional patterns as well as percentage point and mean score changes in terms of the image of the different types of protest, while the lower half of the table depicts equivalent statistics on the perceived success of these actions. The results suggest that even though the majority of the adult public views peaceful protest action in a positive light, public attitudes towards such actions have become less favourable over the period. In 1995 close to two-thirds (64\%) of the general public viewed peaceful action positively, while fewer (57\%) held a similar view in 2016. It is worth noting that this change has not translated into an increase in the share who hold a negative view of peaceful actions, 
Table 1: Changes in the image and perceived effectiveness of peaceful, disruptive and violent protest action between 1995 and 2016 (Col \%)

\begin{tabular}{|l|c|c|c|c|c|c|c|c|c|c|c|}
\hline & \multicolumn{7}{|c|}{ Peaceful } & \multicolumn{3}{c|}{ Disruptive } & \multicolumn{3}{c|}{ Violent } \\
\hline & 1995 & 2016 & Diff. & 1995 & 2016 & Diff. & 1995 & 2016 & Diff. \\
\hline Positive or negative image & 64 & 57 & -7 & 11 & 18 & +7 & 6 & 12 & +6 \\
\hline Positive & 9 & 16 & +7 & 8 & 18 & +10 & 6 & 14 & +8 \\
\hline Neutral & 26 & 26 & 0 & 81 & 63 & -17 & 88 & 74 & -14 \\
\hline Negative & 100 & 100 & $\ldots$ & 100 & 100 & $\ldots$ & 100 & 100 & $\ldots$ \\
\hline Total & 4.50 & 4.47 & -0.03 & 2.59 & 3.13 & +0.54 & 2.19 & 2.63 & +0.44 \\
\hline Mean based on 7-point scale & & & & & & & & \\
\hline Perceived effectiveness & 61 & 46 & -15 & 14 & 29 & +15 & 8 & 21 & +13 \\
\hline Successful & 15 & 22 & +7 & 15 & 21 & +6 & 11 & 21 & +10 \\
\hline Neutral & 25 & 32 & +8 & 71 & 51 & -21 & 81 & 58 & -23 \\
\hline Unsuccessful & 100 & 100 & $\ldots$ & 100 & 100 & $\ldots$ & 100 & 100 & $\ldots$ \\
\hline Total & 4.49 & 4.14 & -0.35 & 2.81 & 3.52 & +0.71 & 2.43 & 3.16 & +0.73 \\
\hline Mean based on 7-point scale & 4.49 &
\end{tabular}

Note: The mean scores are based on the original 7-point scales, with higher values representing a more positive image or greater perceived effectiveness. Source: HSRC Omnibus Feb 1995; HSRC SASAS Round 142016.

but rather a greater tendency towards a neutral or ambivalent position. In contrast to peaceful actions, the share of the population viewing disruptive protest actions negatively showed a distinct decline over the past 22 years from $81 \%$ in 1995 to $62 \%$ in 2016. The shares reporting positive or neutral views showed corresponding increases. We also find a softening in the manner in which violent protest actions are viewed over time, with the share of the population who classify this type of action as negative declining from $88 \%$ to $74 \%$ between the two survey rounds. Although the predominant image of both disruptive and violent protests is still a disapproving one, there appears to be a growing acceptance among the adult public of disorderly forms of protest actions.

As for observable changes in evaluations of the success of different types of protest actions, we find the pattern largely mirrors what was described in relation to the image of such behaviours. A growing share of South Africans are ambivalent or sceptical about the efficacy of this form of political behaviour, with the share who stated that peaceful actions were successful decreasing from 61\% in 1995 to $46 \%$ in 2016 . With respect to disruptive and violent protest actions, despite generally negative assessments, the group viewing such actions as successful in 1995 grew proportionally during the period under review. The percentage of respondents rating disruptive protests as unsuccessful fell from 71\% in 1995 to $51 \%$ in 2016 , while the share regarding violent actions as unsuccessful fell from $81 \%$ in 1995 to $58 \%$ in 2016 . This suggests that disruptive and violent actions are increasingly being seen as effective political tools, while peaceful actions are regarded with mounting scepticism. The scale of change is larger in relation to the perceived effectiveness of protest actions, relative to overall levels of approval. 


\section{Cleavages underlying the attitudinal hierarchy}

The pattern of results described above raises questions about the extent to which this national picture and trend is consistent throughout South African society. Is there broad consensus across socio-economic and demographic lines regarding how protest action is perceived, and have such attitudes been changing in a fairly uniform way for most citizens between 1995 and 2016? We examined whether such a consensus exists or, alternatively, whether fundamental attitudinal cleavages characterise mass opinion on this topic in the country. Table 2 presents mean evaluations and change in the perceived image of three types of protest over the period, based on two important attributes in the South African context, namely population group and educational attainment.

The racial patterns in protest attitudes are particularly interesting. For white adults, attitudes towards all three types of protest actions have become more favourable over the period. By contrast, black African adults have become more negative towards peaceful actions, but more positive in respect of disruptive and violent actions. This pattern also applies to Indian adults, while coloured adults became appreciably more positive about peaceful protest and slightly more partial to disruptive protest, but their image of violence showed a modest decline. Taken together, these shifts suggest subtle racial variations, particularly regarding peaceful protest, while for disruptive and violent protests there is a more common perspective, with the image either improving or remaining stable. Again, it is important to emphasise that the improvements in the image of disruptive and violent actions that were observed still fall within an overwhelmingly negative overall position, but these do represent emerging signs of a notable change in predisposition among the public.

When looking at differences based on educational attainment, it is clear that in 2016 better-educated people were more favourably

Table 2: Subgroup changes in the image of peaceful, disruptive and violent protest action between 1995 and 2016 (mean scores)

\begin{tabular}{|c|c|c|c|c|c|c|c|c|c|}
\hline & \multicolumn{3}{|c|}{ Peaceful } & \multicolumn{3}{|c|}{ Disruptive } & \multicolumn{3}{|c|}{ Violent } \\
\hline & 1995 & 2016 & Diff. & 1995 & 2016 & Diff. & 1995 & 2016 & Diff. \\
\hline \multicolumn{10}{|l|}{ Population group } \\
\hline Black African & 4.80 & 4.47 & -0.34 & 2.79 & 3.22 & +0.43 & 2.41 & 2.76 & +0.35 \\
\hline Coloured & 4.03 & 4.74 & +0.71 & 2.58 & 2.90 & +0.32 & 2.11 & 2.00 & -0.11 \\
\hline Indian/Asian & 4.18 & 4.12 & -0.06 & 2.61 & 2.89 & +0.28 & 1.94 & 2.62 & +0.68 \\
\hline White & 3.60 & 4.33 & +0.73 & 1.80 & 2.70 & +0.90 & 1.40 & 2.15 & +0.75 \\
\hline \multicolumn{10}{|l|}{ Educational attainment } \\
\hline No schooling & 4.40 & 4.46 & +0.05 & 2.55 & 2.99 & +0.44 & 2.36 & 2.41 & +0.06 \\
\hline Primary & 4.56 & 4.41 & -0.16 & 2.84 & 3.20 & +0.35 & 2.32 & 2.43 & +0.11 \\
\hline Incomplete secondary & 4.69 & 4.45 & -0.23 & 2.58 & 3.25 & +0.67 & 2.24 & 2.75 & +0.51 \\
\hline Completed secondary & 4.21 & 4.46 & +0.24 & 2.39 & 3.13 & +0.73 & 1.88 & 2.70 & +0.82 \\
\hline Tertiary & 4.09 & 4.60 & +0.51 & 2.17 & 2.76 & +0.60 & 1.53 & 2.29 & +0.76 \\
\hline
\end{tabular}

Note: The mean scores are based on the original 7-point scales, with higher values representing a more positive image or greater perceived effectiveness. Source: HSRC Omnibus Feb 1995; HSRC SASAS Round 142016. 
disposed towards peaceful protest action than those with low levels of education. This difference was not evident in 1995. In both surveys, the observed effect of educational attainment appears less linear when looking at disruptive and violent action. Further testing will have to be undertaken to accurately discern how exposure to formal education is influencing attitudes towards these two types of protest action in South Africa.

The pattern that is described above may be related to changes in the perceived effectiveness of a particular type of protest over time. We argue that the perceived effectiveness of a protest action could reinforce the positive or negative image of that action. To provide an indication of whether a cognitive belief in the effectiveness of protest does in fact influence one's general predisposition to such actions, controlling for other socio-demographic characteristics, we conducted multivariate analysis. We opted to use an ordered logistic regression approach, since the dependent variables are ordered categorical protest image measures. In Table 3, we present three models that were generated, each corresponding to the general image of peaceful, disruptive and violent protest actions respectively. In the models, we include the perceived effectiveness measures alongside a set of socio-demographic characteristics as independent variables. Odd ratios are presented for ease of interpretation.

With regard to evidence on the sociodemographic determinants of assessments of the image of protest, we find firstly that many of the demographic attributes in the models were statistically insignificant. Neither population group nor age emerged as a significant predictor of the image associated with each type of protest. Furthermore, we find that there is no clear or consistent gender effect. While women on average hold lower peaceful protest approval scores compared to men, there is no significant effect present in the case of the image of disruptive or violent protest actions. These findings are surprising, given the importance attributed to these characteristics in media representations of protest action in South Africa. There was also no effect based on marital status. A second notable finding is that the indicators of socio-economic status included in the models did not produce an especially strong or common effect on attitudes towards the different types of protest action. Employment status was not a significant predictor in any of the models, though educational attainment does exert an influence in two of the three models. In the case of public support for peaceful protest, the association is a positive one, implying that more favourable views of this type of protest are apparent as years of education increase (O.R. = 1.040). Education has an inverse effect on support for disruptive protest action, with approval waning as years of education rise (O.R. $=0.905)$. No statistically significant effect was observed in the third model.

Geography seems to matter, though its effect varies across the three types of protest.

Compared to residents in formal urban areas, those living in informal urban settlements tend to hold a more positive view of violent protest actions (O.R. = 1.582), even when holding all other independent variables constant. A similar relationship was not observed for peaceful or disruptive protests. Those residing in rural traditional authority areas tend to offer more positive views of disruptive protest compared to residents in formal urban areas, while no significant geographic effect is observed in the peaceful protest model. At the provincial level, and using the Western Cape as the reference category, we found that living in any of the other provinces (the only exception being the Eastern Cape) is associated with lower levels of support for peaceful protest actions. The largest difference is between the Western Cape and KwaZulu-Natal (O.R. = 0.371). The provincial 
differences observed in the model may be related to the unique history of protest and the prevailing political context in the Western Cape, and warrants further study. Such distinctive provincial differences were not detected in the other models. Appraisals of disruptive protests are significantly lower in Limpopo and the Northern Cape, ${ }^{21}$ while violent actions are more strongly favoured than average in the Free State.

Table 3: Ordered logistic regression models examining the predictors of the perceived approval of peaceful, disruptive and violent protest action, 2016

\begin{tabular}{|c|c|c|c|c|c|c|}
\hline & \multicolumn{2}{|c|}{$\begin{array}{c}\text { Model I } \\
\text { Peaceful protest }\end{array}$} & \multicolumn{2}{|c|}{$\begin{array}{c}\text { Model II } \\
\text { Disruptive protest }\end{array}$} & \multicolumn{2}{|c|}{$\begin{array}{c}\text { Model III } \\
\text { Violent protest }\end{array}$} \\
\hline & $\begin{array}{l}\text { Odds } \\
\text { ratio }\end{array}$ & Sig. & $\begin{array}{l}\text { Odds } \\
\text { ratio }\end{array}$ & Sig. & $\begin{array}{l}\text { Odds } \\
\text { ratio }\end{array}$ & Sig. \\
\hline \multicolumn{7}{|l|}{ Background variables } \\
\hline Female (ref. male) & 0.780 & * & 0.816 & & 0.888 & \\
\hline Age & 1.008 & & 0.994 & & 0.994 & \\
\hline \multicolumn{7}{|l|}{ Marital status (ref. married) } \\
\hline Widowed, separated or divorced & 1.141 & & 0.806 & & 1.067 & \\
\hline Never married & 1.285 & & 0.901 & & 0.838 & \\
\hline \multicolumn{7}{|l|}{ Population group (ref. Black African) } \\
\hline Coloured & 1.051 & & 1.305 & & 0.774 & \\
\hline Indian & 0.777 & & 1.336 & & 1.395 & \\
\hline White & 0.738 & & 1.149 & & 0.878 & \\
\hline Years of schooling & 1.040 & * & 0.905 & ** & 0.990 & \\
\hline \multicolumn{7}{|l|}{ Employment status (ref. employed) } \\
\hline Retired & 0.894 & & 0.755 & & 0.903 & \\
\hline Unemployed & 1.021 & & 0.797 & & 0.892 & \\
\hline Student & 0.913 & & 1.150 & & 1.178 & \\
\hline Other labour inactive & 1.056 & & 1.000 & & 1.075 & \\
\hline \multicolumn{7}{|l|}{ Geographic type (ref. urban formal) } \\
\hline Urban informal & 0.848 & & 1.465 & & 1.582 & * \\
\hline Traditional authority areas & 0.892 & & 1.402 & * & 1.169 & \\
\hline Commercial farms & 0.959 & & 0.899 & & 1.199 & \\
\hline \multicolumn{7}{|l|}{ Province (ref. Western Cape) } \\
\hline Eastern Cape & 0.797 & & 0.843 & & 1.361 & \\
\hline Northern Cape & 0.603 & * & 0.606 & * & 1.340 & \\
\hline Free State & 0.604 & ** & 0.784 & & 1.669 & * \\
\hline KwaZulu-Natal & 0.371 & 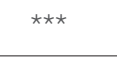 & 1.012 & & 1.410 & \\
\hline North West & 0.452 & *** & 1.082 & & 1.370 & \\
\hline Gauteng & 0.501 & $* \star *$ & 1.018 & & 1.233 & \\
\hline
\end{tabular}




\begin{tabular}{|c|c|c|c|c|c|c|}
\hline & \multicolumn{2}{|c|}{$\begin{array}{c}\text { Model I } \\
\text { Peaceful protest }\end{array}$} & \multicolumn{2}{|c|}{\begin{tabular}{|c} 
Model II \\
Disruptive protest
\end{tabular}} & \multicolumn{2}{|c|}{$\begin{array}{c}\text { Model III } \\
\text { Violent protest }\end{array}$} \\
\hline & $\begin{array}{l}\text { Odds } \\
\text { ratio }\end{array}$ & Sig. & $\begin{array}{l}\text { Odds } \\
\text { ratio }\end{array}$ & Sig. & $\begin{array}{l}\text { Odds } \\
\text { ratio }\end{array}$ & Sig. \\
\hline Mpumalanga & 0.469 & 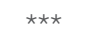 & 0.735 & & 1.371 & \\
\hline Limpopo & 0.541 & ** & 0.315 & 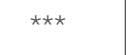 & 0.735 & \\
\hline \multicolumn{7}{|c|}{ Political party identification (ref. ANC) } \\
\hline Democratic Alliance & 0.808 & & 0.619 & * & 0.920 & \\
\hline Unaffiliated & 0.739 & & 0.741 & & 0.774 & \\
\hline Other opposition parties & 0.668 & * & 0.710 & & 0.938 & \\
\hline Undeclared & 0.942 & & 0.735 & & 0.731 & \\
\hline \multicolumn{7}{|c|}{ Perceived effectiveness of protest } \\
\hline Peaceful protests & 2.518 & *** & & & & \\
\hline Disruptive protests & & & 2.107 & 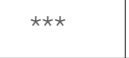 & & \\
\hline Violent protests & & & & & 2.215 & *** \\
\hline Number of obs. & 2815 & & 2795 & & 2821 & \\
\hline Wald $\operatorname{chi}^{2}(28)$ & 359 & & 263 & & 265 & \\
\hline Prob>chi ${ }^{2}$ & 0.000 & & 0.000 & & 0.000 & \\
\hline Pseudo $R^{2}$ & 0.125 & & 0.108 & & 0.124 & \\
\hline
\end{tabular}

Note: ${ }^{*} p<0.05,{ }^{* *} p<0.01,{ }^{* * *} p<0.001$

Source: HSRC SASAS Round 142016.

\section{Concluding discussion}

Moving beyond simple violent/non-violent binary distinctions, we presented data on public attitudes towards three types of protest action in this study. We found that peaceful protest action was viewed more favourably than either disruptive or violent action. The extent of this hierarchy was then explored across different socio-demographic and geographic groupings. No considerable differences were observed between age, gender and race groups. In addition, and perhaps more surprisingly, no significant differences were observed between different class groupings. Noteworthy geographical differences were observed, and these patterns point to how ecological effects shape attitudes towards different types of protest action. Understanding these ecological effects is critical and, we believe, is a key area for follow-up research. This is likely to require exploratory qualitative research, including ethnographies and in-depth interviews, to capture specific geographic realities.

Attitudinal variables were found to be more powerful predictors of whether an individual approved of a specific type of protest action than socio-economic conditions. The perceived success of a specific type of protest action was shown to have a considerable influence on public support. This finding raises the question: when and why does protest action appear successful? We must remember that protest tactics - whether they are peaceful, disruptive or violent - are strategies utilised by certain groups in order to increase their bargaining ability with a specific institution(s). Protest tactics will appear successful to the extent that the institution(s) can be motivated to end the conflict in ways favourable to the protesters' goals. How the institution(s) responds to the tactics of protest 
movements is, therefore, very important to how different types of protest action are viewed. If, for example, the authorities ignore peaceful protest tactics, then such tactics will be seen as ineffective by the general population and public approval for peaceful protest action will decline.

The link between attitudes and behaviour is well known, and the findings showcased in this study are therefore important. Although this relationship is indirect and is mediated by a range of different factors, research has shown that attitudes have a consistently dynamic influence on individual behaviour. ${ }^{22}$ Consider, for instance, if public confidence in violent protest action grew significantly. If more people see violent protest action as effective and approve of it, we would expect to see greater public participation in violent protest activities. A considerable increase in the number and intensity of violent protests would place a substantial strain on law enforcement agencies that are already struggling to cope with existing levels of protest activity. Moreover, an adult population who favoured violent protest tactics would be unlikely to cooperate with the authorities in containing such tactics and arresting the perpetrators.

The study has used two time points (1995 and 2016) to comment on how attitudes towards protest action have changed during the postapartheid period. The data suggests that the general population has become more negative towards peaceful protest actions and more supportive of violent and disruptive actions, even though the predominant view of the latter two types of protest remains negative on average. Although this article contributes to the understanding of mass opinion towards various forms of protest, there are clearly important questions that remain unanswered. The data used for this article contain certain limitations that make it difficult for the authors to be more conclusive about the changing nature of protest beliefs. The absence of more time points in our data series prevents us from providing more detailed commentary on the nature of the observed attitudinal change and how gradual it has been. Furthermore, we cannot be sure how sensitive protest attitudes are to period effects (such as a worker strike or student protest), and public opinion on protest tactics may be quite volatile. Further public opinion work should therefore aim to (1) identify other attitudinal and contextual correlates of protest beliefs, (2) more systematically monitor changes over time to gain a more accurate sense of the dynamism or stability of such attitudes, and (3) explore the relative influence of period effects. In so doing, we would greatly enrich our understanding of what must certainly be considered one of the most distinctive social and political phenomena in contemporary South Africa.

To comment on this article visit

http://www.issafrica.org/sacq.php

\section{Notes}

1 Peter Alexander and Peter Pfaffe, Social relationships to the means and ends of protest in South Africa's ongoing rebellion of the poor: the Balfour insurrections, Social Movement Studies, 13:2, 2013, 204-221.

2 Peter Alexander, Rebellion of the poor: South Africa's service delivery protests - a preliminary analysis, Review of African Political Economy, 37:123, 2010, 25-40.

3 Carin Runciman et al., Counting police recorded protests: based on South African Police Service Data, Johannesburg: Social Change Research Unit, University of Johannesburg, 2016.

4 The literature on protest participation suggests a large number of triggers to explain large-scale protest movements. Influential triggers are discussed by Sidney Tarrow, Power in movement: social movements, collective action and politics, Cambridge: Cambridge University Press, 1994; Charles Tilly, From mobilization to revolution, London: Random House, 1978. For a South African perspective, see Biniam E Bedasso and Nonso Obikili, A dream deferred: the microfoundations of direct political action in pre- and post-democratisation South Africa, The Journal of Development Studies, 52:1, 2016, 130-146; Patrick Bond, South African people power since the mid1980s: two steps forward, one back, Third World Quarterly, 33:2, 2012, 243-264.

5 Research has shown that the experience of national events can have an effect on individual memories, attitudes and actions. This is particularly true if the events occur during a 'critical period' of one's life, such as later childhood, adolescence and early adulthood. See Howard Schuman 
and Amy Corning, Generational memory and the critical period: evidence for national and world events, Public Opinion Quarterly, 76:1, 2012, 1-31.

6 Data is available from the Global Database of Events, Language and Tone Project Database, http://gdeltproject.org.

7 For example, thousands of people died between 1990 and 1994 in Gauteng and KwaZulu-Natal as a result of political contestations. For a detailed review of this violence, see Adrian Guelke, Interpretations of political violence during South Africa's transition, Politikon, 27:2, 2000, 239-254; Karl von Holdt, South Africa: the transition to violent democracy, Review of African Political Economy, 40:138, 2013, 589-604.

8 Data is available from the Social Conflict in Africa Database, www.scaddata.org.

9 Alexander, Rebellion of the poor. For further discussion of the 'rebellion of the poor' thesis, see Alexander and Pfaffe, Social Relationships to the means and ends of protest in South Africa's ongoing rebellion of the poor; Richard Ballard et al., Globalization, marginalization and contemporary social movements in South Africa, African Affairs, 104:417, 2005, 615-634.

10 Richard Pithouse, A politics of the poor: shack dwellers' struggles in Durban, Journal of Asian and African Studies, 43:1, 2008, 63-94; Doreen Atkinson, Taking to the streets: has developmental local government failed in South Africa? in Sakhela Buhlungu, John Daniel and Roger Southall (eds), The state of the nation 2007, Cape Town: Human Sciences Research Council Press, 2007, 53-77.

11 Robert A Dahl, Polyarchy: participation and opposition, New Haven: Yale University Press, 1973; Francis Graham Wilson, A theory of public opinion, Chicago: Regnery, 2013.

12 Andrea Royeppen, How does state security limit the right to protest? State response to popular participation in South Africa, African Security Review, 25:4, 2016, 340-355.

13 Gareth Newham and Andrew Faull, Protector or predator? Tackling police corruption in South Africa, Institute for Security Studies (ISS), Monograph 182, 2011, 65.

14 Karl von Holdt et al., The smoke that calls: insurgent citizenship, collective violence and the struggle for a place in the new South Africa, Johannesburg: Centre for the Study of Violence and Reconciliation and Society, Work and Development Institute, 2011.

15 Carin Runciman et al., Counting police-recorded protests, 25.

16 As described by Runciman et al., Counting police recorded protests, 30-31, the issue of how to handle instances where the three forms of protest are not mutually exclusive has had to be considered in developing a database to monitor changing patterns of protest action in the country. This was achieved by means of a classificatory principle that stipulates that if there is any evidence of violence within the context of a particular protest event (even if it began as a peaceful demonstration), then it is recorded as a violent protest. If there is evidence of disorder, the event is not recorded as orderly, but instead as either disruptive or violent depending on the circumstances. In instances where the coding of protests into the categories is more ambiguous owing to the complexity of real-life situations, this is ultimately resolved through a group review and adjudication process.

17 MarkData was established as a branch of the HSRC in 1981 and remained as such until 1996, when it became an independent private marketing and strategic research company.

18 Throughout the article, we refer to this as the 2016 survey round, even though the fieldwork occurred during 2017. This is because the survey occurred during the HSRC's 2016/17 financial year, which ended on 21 March 2017.

19 Relative to our national population size, the South African HSRC survey samples compare favourably. It is helpful to look to other highly respected national and cross-national survey infrastructures. For instance, in the latest round of the European Social Survey, the sample was 2852 for Germany, 2430 for Russia, 1959 for the United Kingdom and 2070 for France. These countries all have population sizes larger than that of South Africa and yet the samples are in a similar range or smaller.

20 Carin Runciman et al., Counting police-recorded protests.

21 The Odds Ratio for the disruptive action is highest in North West province, although this effect does not achieve statistical significance. In the violent protest model, the Odds Ratio is also lowest in Limpopo, although again this provincial effect is not strong enough to be statistically significant.

22 The Theory of Planned Behaviour hypothesises that individuals' attitudes are major determinants of their behavioural intentions. Although this theory emphasises the effect attitudes have on behaviour, it concedes that situational, normative and individual characteristics also have effects on behaviour. For a comprehensive discussion, see Martin Fishbein and Icek Ajzen, Predicting and changing behavior: the reasoned action approach, New York: Taylor \& Francis, 2011. 